\title{
O DESENVOLVIMENTO E O ESTADO ATUAL DA PESQUISA DO PROCESSO TRADUTÓRIO ${ }^{1}$
}

\section{THE DEVELOPMENT AND CURRENT STATE OF TRANSLATION PROCESS RESEARCH}

\author{
Arnt Lykke JAKOBSEN ${ }^{2}$ \\ Tradução de: Ana Carolina Assunção ZAMPINI ${ }^{3}$ e Igor A. Lourenço DA SILVA ${ }^{4}$
}

\begin{abstract}
Resumo: O interesse pelos estudos da tradução orientados para o processo tem sido ativo nos últimos mais de cinquenta anos. Estudos processuais da tradução (em inglês, translation process research, ou TPR) é o nome que temos utilizado para nos referir a uma abordagem especial, de natureza descritiva, empírica e experimental, dos estudos da tradução que se baseia, mediante o suporte tecnológico, na observação estrita do (micro)comportamento tradutório. Basicamente, a pesquisa do processo tradutório faz uso de programas de key logging, que registram, em tempo real, os acionamentos de teclas e mouse pelo tradutor, e de rastreadores oculares (eye trackers), que registram os movimentos oculares do tradutor sobre uma tela que exibe o texto-fonte e a tradução emergente. Esse método de pesquisa foi desenvolvido como meio de qualificar e reforçar as hipóteses sobre o processo tradutório aventadas com base em relatos verbais, uma vez que fornece dados adicionais, distintos e quantitativos acerca dos mesmos eventos, a partir dos quais podem ser realizadas análises e interpretações complementares. Com esse método, vários processos podem ser diretamente observados em diferentes níveis de refinamento e comparados com aspectos relatados acerca dos processos mentais, os quais permanecem inacessíveis à observação externa. Quais processos mentais subjazem o (micro)comportamento mensurável é algo passível apenas de inferência. A captura de toda a complexidade da tradução claramente requer uma abordagem multimetodológica, e os estudos da tradução devem estar abertos a estender sua curiosidade para além de si próprios, buscando suporte em áreas como a psicologia cognitiva, a psicolinguística, a neurolinguística e a neurociência, as quais também têm ativo interesse pelo que acontece dentro das nossas cabeças.
\end{abstract}

Palavras-chave: Pesquisa do processo tradutório. Rastreamento ocular. Registro de acionamentos de teclas e mouse. Abordagem multimetodológica.

\section{Estudos processuais da tradução}

O nome e a natureza dos estudos da tradução, como se sabe, foram explicitados por James S. Holmes em sua apresentação no Terceiro Congresso Internacional de Linguística

\footnotetext{
${ }^{1}$ Agradecemos ao autor e à editora John Benjamins Publishing Company a gentileza de cederem os direitos para a publicação desta versão traduzida. Referência do artigo original: JAKOBSEN, Arnt Lykke. The development and current state of translation process research. In. BREMS, Elke; MEYLAERTS, Reine; VAN DOORSLAER, Luc. (Ed.). The known unknowns of translation studies. Amsterdã/Filadélfia: John Benjamins, 2014. p. 65-88. $\mathrm{O}$ volume onde o texto original foi publicado se encontra à venda no site da editora John Benjamins: https://benjamins.com/\#catalog/books/bct.69/main Acesso em 13 de dezembro de 2017.

${ }^{2}$ Copenhagen Business School

3 Professora de inglês e tradutora dos pares linguísticos PT-EN/EN-PT, IT-EN/PT, ES-EN/PT. Cursa Bacharelado em Tradução na Universidade Federal de Uberlândia (2013-2017). E-mail: acazampini@gmail.com ${ }^{4}$ Professor adjunto da Universidade Federal de Uberlândia. Tem mestrado e doutorado em Estudos Linguísticos, área de concentração Linguística Aplicada, com foco em Estudos da Tradução, pela Universidade Federal de Minas Gerais. Tradutor PT-EN/EN-PT/ES-PT e revisor desde 2005. E-mails: ials@ufu.br, ialsigor@gmail.com
} 
Aplicada, realizado em Copenhague de 21 a 26 de agosto de 1972, mas seu artigo, a princípio, teve pouco impacto no desenvolvimento dos estudos da tradução. O solene mapa da estrutura dos estudos da tradução foi explicado, mas não foi graficamente incluso na primeira versão do artigo, aparecendo impresso somente em 1987, ano posterior à sua morte. Talvez seja um indicativo da relativa obscuridade das ideias de Holmes por cerca de 15 anos o fato de que Chesterman - que subsequentemente se referiu ao artigo de Holmes diversas vezes (mais diretamente em 2009, nas páginas 13 a 22) - parece não ter tido ciência do trabalho de Holmes ou não o ter achado suficientemente relevante para incluí-lo em seu Readings in Translation Theory, de 1989. Mesmo após a importante republicação do artigo de Holmes, no The Translation Studies Reader (2000, p. 172-185), de Venuti, Toury recentemente reiterou o que escrevera em 1995, no Descriptive Translation Studies - and beyond, ou seja, "ainda se está bastante longe da concretização de toda a sua visão" (TOURY 1995, p. 8; 2012, p. 2), apesar de ter adicionado uma nota de rodapé na edição revisada, dizendo que, "no decorrer dos anos, tem-se recorrido mais comumente às ideias de Holmes”. Certamente, esse é o caso, e o mapa de Holmes é um referencial apropriado dentro do qual este artigo contempla os esforços da pesquisa do processo tradutório (em inglês, translation process research, ou TPR).

\subsection{Como parte dos estudos descritivos da tradução}

A proposta de Holmes foi usar a expressão "estudos da tradução" como o nome de um campo disciplinar, uma nova área empírica com duas ramificações principais, uma "pura" e outra "aplicada" (que engloba a formação em tradução, os auxílios à tradução e a crítica à tradução), sendo o ramo "puro" subdividido em um ramo teórico (teoria da tradução) e um ramo descritivo (estudos descritivos da tradução). O ramo descritivo seria o responsável por "descrever os fenômenos do ato tradutório e da(s) tradução(ões) conforme se manifestam no mundo da nossa experiência", e a tarefa da teoria da tradução seria a de "estabelecer princípios gerais por meio dos quais esses fenômenos possam ser explicados e previstos" (HOLMES, 1972 apud VENUTI, 2000, p. 176). No ramo descritivo, Holmes previu três categorias de estudos: orientados para o produto, orientados para o processo e orientados para a função. Assim imaginou o autor os estudos descritivos da tradução orientados para o processo:

Os estudos descritivos da tradução orientados para o processo voltam-se para o processo ou ato tradutório propriamente dito. O problema do que exatamente 
acontece na "pequena caixa preta" da "mente" do tradutor à medida que cria um novo texto mais ou menos correspondente em outra língua é alvo de muita especulação pelos teóricos da tradução, mas houve muito poucas tentativas de investigação sistemática desse processo sob condições laboratoriais. (HOLMES, 1972 apud VENUTI, 2000, p. 177)

Holmes previu que "métodos altamente sofisticados" desenvolvidos por psicólogos seriam úteis no desenvolvimento dessa variante dos estudos descritivos da tradução, que ele pensou que "poderia se chamar psicologia da tradução ou estudos psicotradutórios".

A "caixa preta" é uma clássica incógnita conhecida nos estudos da tradução. Claramente Holmes acreditava que, com uma pequena ajuda dos psicólogos e por meio de uma investigação sistemática do processo sob condições laboratoriais, a caixa preta poderia ser aberta. Ele, contudo, não especificou mais detalhadamente o que seriam esses métodos altamente sofisticados ou por quais métodos ou meios poderia ser feita essa investigação sistemática do processo ou ato tradutório. Ele estava obviamente descriminando uma incógnita conhecida sem, no entanto, ter uma ideia muito clara de como essa incógnita poderia ser mais bem conhecida. Uma questão importante para o presente trabalho, portanto, é examinar o quanto se sabe, o quanto pensamos que pode ser conhecido agora e até que ponto ainda vamos, talvez indefinidamente, confrontar uma incógnita a ser conhecida. Para tal, primeiro me concentrarei em como e por que o interesse pelos estudos processuais da tradução vem crescendo ao longo dos últimos mais de cinquenta anos; em seguida, examinarei a variante conhecida como pesquisa do processo tradutório desenvolvida pelo CRITT (Center for Research and Innovation in Translation and Translation Technology); por fim, farei um balanço geral e delinearei perspectivas futuras.

\subsection{Primeiros interesses pelos processos}

É interessante observar como, mais de meio século atrás, diversas áreas do conhecimento humano se voltaram para a investigação dos movimentos e processos que levam a um resultado final em vez de apenas se concentrarem na decisão final, no resultado final ou no produto acabado. A psicologia talvez tenha sempre sido fortemente orientada à investigação dos processos (mentais) que levam um estado mental a outro através de fases distinguíveis e previsíveis. Com inspiração na psicologia, desenvolveu-se na linguística o interesse pela psicolinguística e pela neurolinguística, mediante adaptação de metodologias de pesquisa da psicologia e da neurociência ao estudo da linguagem e mediante a um foco nos processos e padrões de processo similar (ou superior) àquele tido na estrutura da linguagem.

O interesse pelo que passa na nossa cabeça é provavelmente perene e fará uso de 
quaisquer métodos que prometam uma nova possibilidade de compreensão. Na psicologia e na antropologia, chamaram à atenção os novos métodos de se explorar como a mente humana funciona: como ela controla nosso comportamento e medeia nossa consciência interna do que acontece na nossa mente e o nosso entendimento de experiência. A psicologia contribuiu com métodos experimentais robustos, e a antropologia proveio métodos para observar, registrar e analisar o comportamento e a interação humana prolongada. Em áreas como ensino de línguas (estrangeiras), leitura e escrita, foi amplamente adotada a mudança de perspectiva: distanciando-se (de alguma forma) do produto, passou-se cada vez mais para a observação e análise do processo, ou dos processos, que levam ao produto. E do ensino e aprendizagem da leitura e escrita e das línguas estrangeiras, foi um pequeno passo para os estudos da tradução, onde esses novos métodos foram rapidamente adotados.

Professores de escrita, ou "produção de texto", especialmente nos EUA, estudavam processos de escrita com base em protocolos observacionais desde o começo da década de 1970. Diversos dos primeiros estudos sobre o processo de escrita combinavam o interesse por esse processo com o interesse pela cognição e desenvolveram modelos processuais de escrita. Como era frequentemente o caso na época em que os computadores estavam começando a transformar nossas vidas, a modelagem dos processos geralmente se dava por meio de fluxogramas. Assim, em seu influente Cognitive Process Model of the Composing Process, Flower e Hayes (1981) descreveram o processo de composição em três etapas principais: planejamento, tradução e revisão. Processos, ou subprocessos, de planejamento consistiam na geração e organização de ideias e na relação entre elas de forma processual e lógica. Os processos de tradução, no uso que os autores fizeram do termo "tradução", consistiam em transformar as ideias organizadas em palavras durante a fase a que os autores por vezes se referiram como fase de redação preliminar (draft). A fase final de revisão consistia nos processos de revisão e edição; e, durante todo o processo, uma função de monitoramento seria responsável por supervisionar todos os processos de leitura, averiguação e releitura do texto atual, avaliando tudo o que foi escrito ou digitado, tanto ao longo quanto ao final do processo. Tal modelo serviria diretamente, pelo menos de forma parcial, como um modelo de como se originaria uma tradução.

Como muitos escritores já afirmaram, o processo de escrita frequentemente contém elementos de descoberta. A famosa indagação de E. M. Forster, "Como posso dizer o que 
penso sem antes ver o que disse?" ("How can I tell what I think till I see what I say?")5, é frequentemente citada para ilustrar esse ponto, que é igualmente relevante para a tradução interlinguística como a conhecemos. Traduzir um texto também é um processo de descoberta, e um tradutor teria toda razão em perguntar: "Como posso saber o significado de um texto (fonte) sem antes tê-lo traduzido?" ou "Como posso dizer como traduzir um texto sem antes ver a minha tradução?” Esse aspecto não apenas sugere uma forte sobreposição criativa entre produção de texto e tradução, como também talvez ajude a entender por que os bibliotecários tradicionalmente categorizam a tradução como parte da literatura.

Os estudos da tradução orientados para a função também foram, de várias formas, uma descoberta do forte elemento de criatividade envolvido no processo tradutório. Toda a primeira metade da influente obra Strategie der Übersetzung (1982), de Hönig e Kussmaul, foi ironicamente intitulada "Das heilige Original" [o original sagrado], em uma demonstração da necessidade de o tradutor agir, mudar e considerar as situações pragmáticas nas quais o texto foi criado e nas quais a sua tradução deveria funcionar para que fosse adequada. Para os autores, tudo dependia da situação pragmática e comunicativa em questão, "die jeweilige Situation" (HÖNIG; KUSSMAUL, 1982, p. 20). ${ }^{6}$

Curiosamente, duas ideias quase diametralmente opostas se chocaram dentro dessa tradição funcionalista, com consequências bastante notáveis para nossa percepção do que é a tradução e para nossas ideias sobre quais processos estão envolvidos na tradução. Uma linha de pensamento, representada primariamente por Katharina Reiss $(1971 ; 1976)$, defendia que o texto-fonte (TF) de alguma maneira contém uma especificação completa do que seria uma tradução "adequada" dele mesmo. Uma identificação cuidadosa da função dominante em um TF através da "übersetzungsrelevante Textanalyse" [análise do texto relevante para a tradução] poderia orientar o tradutor quanto a essa tradução adequada (à exceção de um ou dois gêneros específicos). ${ }^{7}$

Em contraste, a teoria do escopo (Skopos), de Veermer, foi uma expressão radical não apenas do propósito novo e independente a que a tradução serviria, mas também da sua influência determinante sobre o texto traduzido. Ao adotar essa posição, o autor na prática

\footnotetext{
${ }^{5}$ FORSTER, E. M. Aspects of the novel. 1927. Geralmente citado como "Como posso saber o que eu penso sem antes ver o que escrevi?"

${ }^{6}$ Veja, por exemplo, Kussmaul (1991; 2000; 2009).

7 Versões posteriores dessa perspectiva, representadas, por exemplo, por Nord (2005), alteraram a ênfase e reconheceram a importância de considerações sobre o público-alvo; assim, cada vez mais se passou a perceber a capacidade de adaptar um texto-alvo a diferentes públicos e propósitos ou funções como parte da competência de um tradutor profissional.
} 
explorou a ideia de um apoio exclusivo ou mesmo especial nas informações contidas no TF. ${ }^{8}$ A insistência de Vermeer na supremacia do escopo era tão grande que por vezes se entendia que ele estava descartando o TF. Ocasionalmente se chegava a achar que ele estava transformando o apoio na análise do TF em um apoio na análise profunda do escopo do Translat para uma especificação suficiente da tradução, talvez com um pouco de referência ao TF ou a alguns materiais da língua-fonte.

Esse confronto tem relevância não só para os estudos processuais, mas também para a tradução automática, que encontra sérias dificuldades a partir do momento em que não se sustenta a hipótese de que um texto-fonte, de alguma forma, especifica à exaustão sua(s) própria(s) tradução(ões) relevante(s), ou, ao menos, contém pistas suficientes para viabilizar a produção de uma tradução relevante, a qual, então, deve ser produzida de forma criativa. Em um cenário com opiniões tão divergentes, estava patente que não havia um caminho direto da superfície de um TF para um texto-alvo (TA) significativo e que o processo ou os processos envolvidos eram complexos e não requeriam apenas muito esforço mental, mas também muito esforço criativo (cf. KUSSMAUL, 2000). Não obstante, houve uma sensação de se haver libertado os estudos da tradução da linguística, da filologia, da tradução literária e, não menos importante, da falácia da equivalência. Desse ponto em diante, pouquíssimos profissionais no âmbito dos estudos da tradução assumiriam que ideias como "semelhança de significado" ou "semelhança de efeito comunicativo" poderiam ser mais do que um guia imperfeito para a tradução.

\subsection{Protocolo de verbalização do pensamento em voz alta}

O interesse pelo estudo do processo tradutório recebeu, na década de 1980, forte estímulo com a publicação de um novo método para investigação dos processos mentais: o método de verbalização do pensamento em voz alta (em inglês, think-aloud protocol, ou TAP), apresentado por Ericsson e Simon (1980; 1984; 1993). Utilizando essa forma de verbalização como método preferencial para obter dados verbais e concebendo a tradução como basicamente um processo de tomada de decisão (para o qual o fluxograma era uma analogia sugestiva), os pioneiros dos estudos processuais da tradução Gerloff (1987), Krings (1986; 1995; 2001), Séguinot (1989), Danks et al. (1997) e Lörscher (1991), seguidos por Tirkkonen-Condit e Jääskeläinen (2000) e muitos outros, lograram êxito em estabelecer um complexo inventário de operações com palavras e sentidos realizadas por tradutores,

8 A fissura entre as duas posições é visível em seu livro conjunto Grundlegung einer allgemeinen Translationstheorie (REISS; VERMEER, 1984). 
operações essas frequentemente chamadas de "estratégias". 9 O número de estratégias identificadas culminou na obra Texte reparieren (KRINGS, 1995), que listou oito categorias principais de processos relativos ao texto-fonte, à produção de texto, à tradução automática (Krings investigava a pós-edição), avaliação do texto-alvo, o trabalho de documentação, a escrita física, a tarefa global e a não tarefa. Essas categorias foram, posteriormente, subdivididas em 85, várias delas com subcategorias adicionais, chegando-se a um total de mais de 200. Todas essas categorias foram estabelecidas com base nas verbalizações do pensamento em voz alta pelos participantes. Em retrospecto, talvez seja um tanto quanto surpreendente que os participantes tenham expressado uma avaliação do próprio texto-alvo, mas não do texto-fonte; e pode ser que, mais tarde, a leitura (assim como a escrita) talvez tivesse sido percebida e também considerada um processo físico, de modo que o número de categorias processuais teria sido ainda maior.

Na edição revisada de Protocol Analysis, Ericsson e Simon (1993) discutiram e rebateram críticas à sua abordagem, que compreende a obtenção de dados concomitantemente com os processos cognitivos que eles diziam estudar e, por isso, muito provavelmente relacionados a esses processos, muito embora a atividade concomitante assim suscitada não é uma atividade associada necessária ou de ocorrência natural no que diz respeito ao processo sob investigação. A despeito das alegações feitas por Ericsson e Simon, o método potencialmente enviesa a atividade cognitiva primária sob escrutínio, fenômeno esse que é frequentemente chamado de "reatividade" (BOWLES, 2010). Krings (1995; 2001) observou, em seus experimentos, que o método de verbalização do pensamento em voz alta atrasava a tradução em aproximadamente $25 \%$, mas não sugeriu que afetava a natureza do processamento. Nos experimentos relatados por mim (cf. JAKOBSEN, 2003, traduzido neste volume), também foi observado esse efeito de retardamento. Mais importante ainda: os experimentos que comparavam dados oriundos de registro de acionamentos de teclas e mouse (key logging) com e sem a verbalização concomitante do pensamento em voz alta também indicaram que essa verbalização tinha um efeito degenerativo na segmentação. Portanto, ao menos em experimentos relativos à tradução, a verbalização concomitante parece ter um efeito negativo no processamento e parece ter um preço a ser pago em termos de carga cognitiva adicional. Esse achado só foi possível por meio do registro dos acionamentos de teclas e mouse, que foi o começo da variante dos estudos processuais da tradução que se tornou conhecida como pesquisa do processo tradutório.

\footnotetext{
9 Jääskeläinen (2002) estabelece um traçado dos estudos da tradução baseados em protocolos de verbalização do
} pensamento em voz alta, desde os primórdios até 2001. 


\section{Pesquisa do processo tradutório}

A pesquisa do processo tradutório tem se desenvolvido a partir da combinação do registro dos acionamentos de teclas e mouse (key logging) e do rastreamento ocular (eye tracking), juntamente com o aporte da análise estatística e computacional dos dados obtidos. Um registro dos acionamentos de teclas e mouse é uma gravação completa de todas as mudanças editoriais realizadas por um tradutor durante a digitação da tradução (ou de outro texto). Exclusões, revisões e adições são evidências das primeiras ideias e das reconsiderações sobre essas primeiras ideias. Assim, o registro preserva o histórico de todas as decisões tomadas ao longo do percurso, ou seja, o processo de tomada de decisão que levou à versão final. Como os acionamentos de teclas e mouse são registrados em tempo real, é possível observar o ritmo temporal do processo de produção textual. Palavras e sentenças raramente são escritas (i.e., digitadas) em um ritmo constante, sendo quase sempre produzidas em grupos (segmentos) de palavras. Combinada com o rastreamento ocular, a análise dos acionamentos de teclas e mouse pode ser utilizada para mensurar uma espécie de tempo de reação - ou "intervalo olho-tecla", de acordo com Dragsted (2010) -, que seria o tempo decorrido entre a primeira fixação em uma palavra do texto-fonte e o início da digitação da palavra correspondente no texto-alvo. O registro dos acionamentos de teclas e mouse por si só pode ser empregado para identificar padrões no comportamento tradutório, especialmente no que diz respeito a mudanças editoriais, segmentação das unidades de produção e distribuição da duração das pausas. Contudo, quando se adicionam informações do percurso do olhar (gaze) e se registram os movimentos oculares a uma taxa de aproximadamente mil vezes por segundo, obtém-se uma visão muito mais minuciosa de como o significado é compreendido, retrabalhado e formulado em um novo texto.

\subsection{Registro dos acionamentos de teclas e mouse}

Aproveitando-se do fato de que, na década de 1990, a maioria dos textos e das traduções era digitada em teclados de computador, alguns programadores desenvolveram um programa para registrar, reproduzir e exibir diferentes representações do processo pelo qual teclas e mouse eram acionados em tempo real para estudos dos processos de escrita (e.g., STRÖMQVIST; KARLSSON, 2002, com o ScriptLog) e dos processos de tradução (e.g., o Translog concebido por mim e programado por Lasse Schou), além de processos mais abrangentes como aqueles registrados pelo Inputlog (LEIJTEN; VAN WAES, 2006). Por esse 
método, pode-se fazer um registro completo de todos os acionamentos de teclas e mouse efetuados durante a produção de um texto, como erros de digitação, pausas, exclusões, alterações, cliques no mouse e movimentos do cursor. Um certo padrão temporal da produção de texto era geralmente observável, e assumia-se que refletia o ritmo cognitivo em que o processamento ocorre. A esse respeito, Schilperoord (1996) observou o padrão temporal hierárquico das pausas entre os segmentos quando do ditado oral de documentos jurídicos.

A minha própria invenção do Translog (em 1995) ${ }^{10}$ foi em resposta a uma pesquisa pessoal frustrada tentando extrair sentido dos dados de verbalização do pensamento em voz alta. Os dados obtidos foram, em sua maioria, muito ricos e sugestivos, até mesmo sedutores, no sentido de que os dados verbais frequentemente pareciam ser descrições diretas dos processos que esperávamos identificar ou até pareciam ter potencial de explicação (por exemplo, de escolhas feitas a partir de diferentes soluções distintas que haviam sido consideradas). No entanto, muitas vezes e especialmente com profissionais, havia pouca riqueza de verbalização ao mesmo tempo em que se identificavam desempenho e execução rápida e de qualidade. Esse fenômeno foi observado por muitos outros e tratado com bastante competência a partir de considerações sobre a automação de processos que levam a processos rotinizados ou mesmo a processos não conscientes desenvolvidos como parte da expertise (TIRKKONEN-CONDIT， 2005; TIRKKONEN-CONDIT; JÄÄSKELÄINEN， 2000; ERICSSON et al., 2013).

Um grave obstáculo existente quando se tenta fazer inferências sobre o processo cognitivo apenas com base nos acionamentos de teclas e mouse é que a maioria dos processos relevantes se dá antes mesmo de os acionamentos serem executados. Experimentos iniciais indicaram que muitas sugestões espontâneas e falsos começos eram digitados porque era muito fácil corrigir problemas usando o teclado. A impressão inicial era a de que (muitos)

${ }^{10}$ A versão de 1995 foi criada para o sistema operacional DOS e programada em Pascal 5.5 pelo meu filho, Lasse Schou. A primeira versão para Windows (3.1.), batizada de Translog2000, foi lançada ao final de 1999 e também programada por Schou em Delphi 6. No contexto do projeto Eye-to-IT, financiado pela União Europeia, ele reprogramou totalmente o Translog, dessa vez utilizando linguagem C\# e a plataforma .NET, da Microsoft, bem como formatos de dados em XML e Unicode8. As principais adições funcionais do programa foram a sua capacidade de registrar e reproduzir dados de rastreamento ocular de forma sincronizada com os acionamentos de teclas e mouse e a sua capacidade de interagir com um programa de mapeamento do olhar (gaze) associado às palavras. A versão completa desse programa nunca chegou a ser distribuída para além dos parceiros do projeto, mas uma versão limitada, sem os componentes de rastreamento ocular e de mapeamento do olhar associado às palavras, foi distribuída como Translog2006 (ainda disponível em <www.translog.dk>). Mais recentemente, o professor Michael Carl e colaboradores do CRITT, da Copenhagen Business School (CBS), na Dinamarca, desenvolveram o Translog-II (a partir do código anterior do Translog), com uma opção de plug-in para rastreamento ocular. Esse programa pode ser baixado gratuitamente da página $<$ https://sites.google.com/site/centretranslationinnovation/>, no menu "Resources", onde também constam manuais de instrução. 
tradutores tinham tal excelência em digitação que um registro completo de sua digitação continha informações que, do contrário, só poderiam ser obtidas por meio da verbalização concomitante do pensamento em voz alta. Um registro de acionamentos de teclas e mouse tipicamente grava um grande número de soluções provisórias, mas, do ponto de vista inferencial sobre a cognição envolvida no processo tradutório, o fato é que os acionamentos de teclas e mouse ocorrem somente quando já se deu a maioria dos processos referentes à porção do texto que se está examinando. Os acionamentos de teclas e mouse então vêm ao final do processo de tradução ou de (pós-)edição. Primeiro, há a leitura e a construção do significado do texto-fonte. Em seguida, há a negociação mental de como esse significado pode ser organizado em uma representação na língua-alvo; e só depois há a digitação dessa nova representação. O que está refletido na atividade de digitação é, portanto, a liberação de um segmento de informação processado e temporariamente disponível na memória de trabalho.

O processamento ótimo em termos de tradução humana envolveria um constante suprimento de significado do TF processado e mapeamento do TA alimentando a memória de trabalho em ritmo tal que o tradutor consiga digitar (ou ditar) continuamente à máxima velocidade. Contudo, já que essa situação raramente ocorre - ao menos em condições experimentais - em intervalos de tempo mais longos do que cerca de meio minuto (JAKOBSEN, 2005a; 2005b), os acionamentos de teclas e mouse para produção textual tendem a ser claramente segmentados em unidades que refletem as porções de significado que foram processados ou imediatamente antes dos acionamentos de teclas e mouse, ou em sobreposição em certa medida ao período de digitação, ainda que tendo um início anterior a este.

\subsection{Identificação e análise dos movimentos oculares dos tradutores}

Ao se adicionar o rastreamento dos olhos dos tradutores à medida que leem um textofonte na tela de um computador e digitam sua tradução nessa mesma tela, passa-se a obter dados desde o exato começo do processo. De fato, obtêm-se os dados do processo do começo ao fim, porque os movimentos oculares estão envolvidos desde o início da primeira atividade de leitura até que a palavra final do TA seja olhada ou a última mudança seja visualmente monitorada. Por definição, os digitadores são capazes de digitar sem ter que olhar

simultaneamente para o teclado, mas até mesmo eles frequentemente usam os olhos para monitorar a atividade de digitação, tanto olhando para o teclado ocasionalmente (e.g., para 
identificar teclas raramente usadas) quanto visualmente monitorando, de tempo em tempo, a sua produção textual na tela do computador. Logo, o modo como os tradutores leem e monitoram o texto (considerando que o TF e o TA estão em uma mesma tela) é bem diferente do modo como o texto é lido na maioria dos estudos sobre leitura.

Os movimentos oculares de um tradutor fornecem uma imagem detalhada do complexo processamento envolvido na construção de significado a partir de uma sequência de símbolos verbais e na representação desse significado nos símbolos de uma nova língua. Basicamente, a leitura progride da esquerda para a direita (em sistemas de escrita nessa direção) ao longo de uma linha de cada vez e do fim de uma linha para o início da próxima linha abaixo, mas ler não é de forma alguma uma simples sucessão de fixações unidas por sacadas de avanços no olhar. Rayner e Pollatsek (1989), Rayner (1998), Radach et al. (2004) e muitos outros mostraram que o cálculo da amplitude de uma sacada é um processo altamente complexo, que depende não apenas de uma percepção parafoveal do tamanho da palavra, mas também de parâmetros como a probabilidade de ocorrência e a familiaridade com palavras e conceitos específicos. Sempre que a construção de significado falha temporariamente, uma sacada regressiva move os olhos de volta a uma parte anterior do texto para uma nova inspeção. As fixações se diferem consideravelmente entre si no que diz respeito tanto à sua duração temporal quanto ao número de vezes que um mesmo item de uma língua pode vir a ser fixado.

A relação entre o que os olhos estão fazendo em qualquer dado momento e o que a mente está processando não é tão direta como originalmente assumida por Just e Carpenter (1980). Às vezes, a mente está à frente dos olhos e processa uma informação representada por uma palavra em que os olhos ainda não fixaram. Às vezes, os olhos se movem à frente tão rápido que a mente fica para atrás e tem que tentar alcançá-los. Tal desalinhamento temporal pode fazer com que uma palavra anterior ou posterior seja fixada por mais tempo, mesmo quando o processamento, na verdade, corresponde a um item vizinho. Por isso, há ao menos três maneiras diferentes pelas quais os olhos podem responder à dificuldade no processamento: fixando-se em um item por mais tempo; movendo-se para a frente (e fixandose em uma palavra subsequente enquanto esperam a mente alcançá-los); ou executando uma sacada regressiva e refixando-se em outras palavras que já foram lidas. A pesquisa com rastreamento ocular está investigando os detalhes da relação olho-mente, na qual os olhos parecem se comportar como um cachorro preso a uma coleira pela mente em vez de haver uma relação direta entre eles. Embora qualquer nova hipótese sobre essa relação venha a ser 
relevante para a pesquisa do processo tradutório (e para os estudos da tradução em geral), o interesse específico da pesquisa do processo tradutório reside em explorar o tipo especial de leitura que está envolvida na produção de uma tradução escrita.

Dados do olhar nos fornecem subsídios muito mais valiosos do que aqueles fornecidos pelos registros de acionamentos de teclas e mouse, os quais basicamente só capturam, em tempo real e com precisão de milésimos de segundo, o momento em que uma tecla é pressionada e qual tecla é essa. Um registro também pode conter outras informações, como o tipo ou grupo do qual a tecla faz parte, o número do acionamento de tecla na sequência de letras do texto-alvo emergente e as coordenadas de sua posição na tela do computador, mas os dois parâmetros fundamentais são: qual tecla e quando? Isso significa que, se nenhuma tecla é pressionada em um intervalo de 30 segundos, nenhum dado é gravado durante esse tempo.

Os rastreadores oculares, por sua vez, funcionam de forma bem diferente. Eles tipicamente registram, a uma velocidade entre $60 \mathrm{~Hz}$ e $2000 \mathrm{~Hz}$ (i.e., entre 60 e 2000 vezes por segundo), as coordenadas $\mathrm{x} / \mathrm{y}$ do pixel da tela em que se identificou a fixação dos dois olhos do participante. Assim, se houvesse um intervalo de 30 segundos sem dados oculares (por exemplo, porque o participante estava olhando pela janela e não para a tela), um rastreador ocular de $1000 \mathrm{~Hz}$ poderia reportar, em 30.000 linhas, cada qual com um registro de tempo diferente, que nenhum dado ocular foi gravado.

A gravação em alta frequência dos movimentos oculares é necessária porque nossos olhos se movem muito rápido e estão extrema e ativamente ocupados em realizar uma sucessão constante de fixações relativamente estacionárias seguidas por "saltos" muito rápidos ("sacadas") quando traduzimos. Em uma leitura normal, as fixações tipicamente duram cerca de $250 \mathrm{~ms}$ e as sacadas duram entre 20 e $30 \mathrm{~ms}$, dependendo do seu comprimento, o que significa que, a segundo de uma tarefa inteira, os olhos realizam aproximadamente quatro sacadas e quatro fixações em diferentes partes dos textos na tela.

A maioria das pesquisas sobre leitura foi feita com base na leitura de um texto monolíngue, mas o tipo de leitura encontrado na tradução é bem diferente, em sua maior parte porque requer a alternância entre dois textos (um existente e outro emergente) em duas línguas diferentes. Sabe-se, já há muito tempo, que os leitores têm comportamentos diferentes dependendo do propósito para o qual estão lendo. Já na década de 1950, Alfred L. Yarbus observou que a tarefa dada a um indivíduo influencia consideravelmente os seus movimentos oculares. Se é pedido aos participantes de pesquisa que leiam um texto que traduzirão mais tarde, eles automaticamente o lerão de maneira diferente daquela como leriam se lhes fosse 
dito que teriam de responder a questões de compreensão para checar seu entendimento sobre o texto. Em experimentos realizados em 2007 e 2008, Jakobsen e Jensen (2008), traduzidos neste volume, identificaram que o comportamento e a atenção visual eram altamente dependentes do tipo de tarefa de tradução que o tradutor estava realizando. Ler um texto para compreensão envolve menos fixações que ler um texto em voz alta, por exemplo; e digitar uma tradução tipicamente envolve um número muito maior de fixações, porque ler ao mesmo tempo em que se digita uma tradução envolve uma mudança constante de atenção visual, indo-se da leitura do TF para o monitoramento da produção do TA e, em seguida, retornandose ao local aproximado do TF que estava sendo lido. Isso faz com que a leitura seja altamente descontínua e frequentemente resulta em várias fixações antes de se localizar o ponto original de leitura. Uma situação de pós-edição é igualmente complexa. Os dois textos envolvidos são o texto-fonte e a tradução dele fornecida por um sistema de memória automática, tradução essa que o pós-editor revisa fazendo constantes referências ao TF. Algumas interfaces operam com mais de duas janelas, o que complica mais ainda o trajeto dos olhos.

O rastreamento ocular não só produz mais dados, mas também fornece dados com maior refinamento, de modo que, seguindo os movimentos oculares, conseguimos uma perspectiva muito mais próxima da maneira como o texto-fonte é lido e como a compreensão avança, bem como logramos uma perspectiva muito mais próxima da quantidade de trabalho de monitoramento em que os olhos estão envolvidos à medida que se leem porções do TF, se verifica a digitação, se relê uma porção do TF e se move o olhar da tentativa de solução para o texto-alvo de volta para o TF e, mais uma vez, para o TA, talvez por diversas vezes. Tal atividade ocular constrói uma imagem muito mais detalhada de certezas, incertezas, decisões mais e menos seguras, conferências e emergência de novas soluções. Mais importante ainda: a despeito da semelhança da relação olho-lente com uma relação cão-coleira, essa atividade fornece uma demonstração gráfica exata de quais unidades de processamento estão em curso a qualquer dado momento.

\subsection{Três pressupostos básicos da pesquisa do processo tradutório}

Desde o princípio, a pesquisa do processo tradutório (TPR) partiu de três pressupostos básicos. O primeiro é que a atividade cognitiva ("mental") apresenta correlatos comportamentais observáveis e mensuráveis, que podem ser registrados como dados de atividade do usuário. Em referência à interseção mente-cérebro, podemos expressar essa questão dizendo que as experiências que temos na mente têm uma expressão física no cérebro 
e podem ter outras expressões diretamente observáveis no corpo (e.g., expressões faciais, reações galvânicas e de outras naturezas na pele, gestos, movimentos corporais, movimentos da cabeça, movimentos oculares, movimentos dos órgãos de fala quando da expressão oral e movimentos das mãos e dos dedos quando da escrita e da digitação). Trata-se, nesse caso, de (micro)comportamentos que ocorrem fora da caixa preta, mas se presume que sejam afetados por processos geralmente conscientes que ocorrem dentro dela. A fala e a escrita são, obviamente, manifestações corporais dessa natureza, embora normalmente as processemos pelo conteúdo, não como uma evidência comportamental dos processos mentais. Esse é, portanto, o pressuposto da correlação mente-cérebro-comportamento.

O segundo pressuposto, inspirado por pesquisadores como Goldman-Eisler (1972), Butterworth (1980) e Schilperoord (1996), é que as latências ("pausas") entre tais manifestações comportamentais e microcomportamentais nos dados de atividade do usuário são pistas tão importantes para a cognição quanto as próprias manifestações registráveis. Esse é o pressuposto da correlação problema-esforço-de-processamento-duração.

O terceiro, e menos importante, dos pressupostos é que a triangulação de dados quantitativos obtidos via equipamentos computacionais com dados qualitativos do mesmo evento, obtidos, por exemplo, em sessões de verbalização concomitante do pensamento em voz alta ou em sessões de verbalização consecutiva (com algum auxílio externo à memória), têm o potencial de levar à geração de hipóteses mais robustas. Temos utilizado a "triangulação" para nos referirmos a análises de conjuntos de dados combinados relativos a um mesmo evento de tradução, mas primordialmente como uma metáfora que sugere uma convicção de que é necessária uma abordagem multimetodológica. A tradução é uma atividade complexa que combina várias habilidades. Envolve habilidades de leitura e escrita em pelo menos duas línguas mais a habilidade de reformular o sentido de uma língua para outra, operando frequentemente em diversos meios (oral/aural, visual, impresso e sinalizado). Ela serve a incontáveis funções comunicativas e sociais, e não pode ser completamente capturada e compreendida por meio de uma única perspectiva metodológica. Apenas uma abordagem multimetodológica nos permitirá uma visão global. Esse é o pressuposto multimétodo-hipóteses-mais-robustas, que está de perfeito acordo com a visão original de Holmes em relação aos estudos da tradução.

\subsubsection{Manifestações comportamentais do processamento tradutório}

Apesar de haver muita especulação e introspecção na pesquisa do processo tradutório, 
o primeiro pressuposto implica que a última instância de apelo da área são sempre os dados empíricos, obtidos idealmente em situações reais de tradução, mas majoritariamente, até o momento, obtidos em simulações de situações reais de tradução realizadas em laboratório. A conhecida incógnita aqui é em que medida os achados feitos em um ambiente laboratorial podem ser utilizados para prever um comportamento na vida real. $\mathrm{O}$ efeito do ambiente laboratorial no desempenho de cada participante parece variar consideravelmente, o que torna tal projeção muito difícil no nível do indivíduo.

Para minimizar distorções da realidade e adquirir um nível aceitável de validade ecológica, é importante disponibilizar uma atmosfera aconchegante no laboratório. Os participantes devem ser cuidadosa e honestamente preparados para o(s) tipo(s) de tarefa(s) que lhe será(ão) solicitada(s) em um experimento (sem, contudo, revelar o propósito específico da pesquisa); e, em havendo a possibilidade de escolha, devem ser empregadas tecnologias não invasivas. Há uma grande vantagem em fazer pesquisas em laboratório, onde é possível exercer um controle considerável sobre muitas variáveis (e.g., o recrutamento de participantes, as tarefas e condições experimentais, os recursos disponíveis e as ferramentas de observação e gravação) e onde são fáceis a obtenção e a coleta de dados. Tudo isso é muito mais difícil em estudos de campo em ambientes naturalísticos, mas é claro que um laboratório é um laboratório, e o desempenho de um participante nos experimentos de tradução, ou em outros tipos de tarefas que requeiram habilidades humanas, é potencialmente bem diferente do desempenho desse mesmo participante na vida real.

Cada tecnologia impõe limitações distintas a um experimento. No CRITT, na CBS, usamos diferentes versões do Translog para registrar e cronometrar os acionamentos de teclas e mouse. A interface tem seguido o padrão do Windows desde 2000, sendo muito simples de utilizar para os fins solicitados aos participantes. Ainda assim, para a maioria dos participantes, trata-se de um programa diferente, e às vezes eles se deparam com a situação de que algumas funções esperadas não estão disponíveis ou funcionam de uma maneira um pouco diferente do usual em programas do dia a dia. Em tais casos, a funcionalidade do programa pode distorcer os dados. A ausência de uma funcionalidade de navegador dentro do Translog é, não raramente, criticada tanto por participantes quanto por pesquisadores. Os participantes frequentemente reclamam que não lhes é natural traduzir sem acesso instantâneo a informações na internet, e muitos pesquisadores, que veem as pesquisas na internet como dados importantes para entender os processos de tradução, sentem que é desnecessariamente complicado ter de rodar um programa de captura de tela (screen recording) 
concomitantemente com o Translog para obter essa informação. Tais reclamações indicam tanto a precariedade da projeção direta dos resultados obtidos em laboratório para situações da vida real quanto a dependência crescente dos tradutores em relação a algum tipo de suporte eletrônico para a produção de suas traduções.

$\mathrm{O}$ foco em acionamentos de teclas cronometrados, em que o número de acionamentos de teclas ou "eventos" era facilmente divisível (de forma automática) em acionamentos de teclas de produção de texto, acionamentos de teclas de eliminação de texto, acionamentos de teclas de movimento de cursor, cliques do mouse e operações diversas (e.g., copiar e colar), consistia em uma vantagem distintiva do ponto de vista da pesquisa. Esse foco nos permitia gerar automaticamente um perfil simples da produção textual de um participante e, quando combinada com o total de tempo despendido na tarefa, também obter uma medida bastante simples da velocidade da produção textual do participante (número de acionamentos de teclas de produção de texto por minuto) e da eficiência da produção textual (número de acionamentos de teclas de produção de texto dividido pelo número total de acionamentos de teclas). Nenhuma dessas medidas, contudo, informava sobre a qualidade do produto, é claro; e se há de fato uma ligação entre o processo e a qualidade do produto final, ela ainda não foi identificada.

A conhecida incógnita que estávamos investigando primordialmente era qual o princípio ou mecanismo que desencadeava a divisão ou a segmentação do texto-alvo emergente, que era diretamente visível na reprodução (acelerada) das gravações do Translog. Quanta variação haveria de indivíduo para indivíduo? A variação interindividual seria um efeito das diferenças de aptidão na digitação? A variação teria correlação com os diferentes níveis de expertise em tradução? Os segmentos variariam de acordo com a direcionalidade da tradução? Ou com o nível relativo de bilinguismo do tradutor? Ou com as habilidades de leitura e análise sintática na língua-fonte? Ou com as habilidades de escrita na língua-alvo? Em que medida a variação decorreria da relação ou falta de relação tipológica entre as duas línguas envolvidas? O tipo de texto seria um parâmetro relevante? Como os segmentos se correlacionariam com as unidades gramaticais como palavras, sintagmas e orações? As fronteiras dos segmentos coincidiriam com as fronteiras sintáticas do texto-fonte/texto-alvo, ou será que coincidiriam com dificuldades tradutórias em termos de mapeamento semântico? E, o que era crucial: o que estaria acontecendo nesses intervalos? Haveria algum tempo entre os segmentos despendido com o monitoramento do texto anterior? Se sim, quanto tempo seria despendido? Ou será que todo o tempo ou parte dele seria despendido planejando o novo 
texto? De um ponto de vista metodológico, também era importante identificar se haveria uma reatividade potencial da verbalização concomitante do pensamento em voz alta e indagar se a segmentação estaria sendo afetada pela verbalização concomitante nas tarefas que envolviam a verbalização do pensamento em voz alta. Uma linha de investigação mais orientada para a cognição poderia indagar se a segmentação refletiria as unidades de processamento em um nível mais profundo, e talvez mais primitivo, que aquele representado pela análise gramatical tradicional e ser um reflexo da quantidade de informação que nossas memórias de trabalho são capazes de processar de uma vez. Ou será que a segmentação poderia ser vista como um ritmo cognitivo básico de alternância entre períodos de ativação e descanso? As segmentações que víamos seriam uma externalização do trabalho de nossas mentes a partir daquilo que poderia ser entendido como unidades de tradução?

Todas essas circunstâncias, e muitas outras, são potencialmente codeterminantes da emergência intermitente de um novo texto-alvo, e todas as questões acima foram de fato alvo de pesquisa nos últimos anos. A adição dos dados de rastreamento ocular compeliu o nível de análise para um nível muito mais refinado, que, por sua vez, gerou novas questões. Apesar de muitas tentativas de respostas terem sido feitas, muito ainda permanece insuficientemente explorado.

\subsubsection{Quando uma pausa é uma pausa, e o que acontece nela?}

Ao estudarem o processo tradutório de forma experimental, os pesquisadores não podiam superestimar a importância dos diferentes níveis de observação e análise, do "refinamento" de seus dados e seus conceitos analíticos, e do tipo de padrão que estavam buscando nos dados. Se os dados são registrados com precisão de milésimos de segundo (ms), regularidades (por critério temporal) podem ser encontradas em todos os níveis. Poderia ser, por exemplo, em manifestações com a duração de apenas $1 \mathrm{~ms}$, com pausas intervenientes variando entre $80 \mathrm{~ms}$ e $250 \mathrm{~ms}$. Em um registro dos acionamentos de teclas e mouse, tal sequência pode representar uma digitação contínua; e, se nossa pesquisa objetivasse a identificação da variação temporal entre acionamentos de teclas e mouse, uma pausa poderia ter uma duração típica entre $80 \mathrm{~ms}$ e $250 \mathrm{~ms}$. Se nossa pesquisa visasse analisar as transições entre os acionamentos de teclas e mouse identificando se eles coincidiriam ou não com as fronteiras dos morfemas, nossa ideia de duração típica de uma pausa poderia ainda ser a mesma; porém, se esperássemos que ocorreria um processamento adicional nas fronteiras dos morfemas, poderíamos esperar pausas um pouco mais longas nesse caso, muito embora o 
nível geral de refinamento possivelmente pudesse ser o mesmo. Em contrapartida, se quiséssemos estabelecer unidades de processamento em um nível superior (e.g., fronteiras entre os segmentos observáveis a partir dos quais o texto-alvo tende a ser produzido), uma pausa poderia talvez ser mais próxima de um intervalo entre $2000 \mathrm{~ms}$ e $5000 \mathrm{~ms}$.

A resolução (ou grau de refinamento) da tecnologia utilizada para nossas gravações estabelece o limite inferior do que podemos considerar como uma pausa; porém, a definição do que se considera como pausa depende, ao menos em princípio, inteiramente do fenômeno que o pesquisador decidiu investigar. Por que apenas em princípio? Porque, à medida que exploramos o ritmo com o qual as traduções parecem ser produzidas, podemos, ou ao menos esperamos, observar que pausas muito curtas ou muito longas, tanto nos dados dos acionamentos de teclas e mouse quanto nos dados de movimentos oculares, se encontram distribuídas de forma desigual e tendem a se agrupar em torno de certas faixas de duração determinadas por limiares, revelando estrutura. Quando Schilperoord (1996) estudou os ditados orais de documentos jurídicos entre advogados, ele identificou que as pausas eram escalares e se tornavam progressivamente mais longas com o aumento do tamanho da unidade (sintática) ditada. As durações das pausas eram mais longas entre os sintagmas que entre as palavras, mais longas entre as orações que entre os sintagmas, mais longas entre as sentenças que entre as orações e mais longas entre os parágrafos que entre as sentenças. Em termos cognitivos, esse resultado faz todo sentido. Quanto mais longa a unidade produzida, mais tempo é necessário para seu planejamento e monitoramento.

Tomando como base os resultados de Schilperoord, Immonen (2006) conduziu um estudo sobre a duração das pausas na produção de textos monolíngues em comparação com a produção de textos em condições interlinguísticas (i.e., tradução). Trabalhando com o Translog, a autora conseguiu aumentar o refinamento de seu estudo em comparação com o de Schilperoord, investigando a duração da pausa até o nível mínimo dos intervalos intercaracteres dos acionamentos de teclas. Ela identificou que um aumento progressivo na duração da pausa entre unidades de produção de texto cada vez maiores se aplicava desde os intervalos entre os acionamentos de tecla no caso de produção de texto monolíngue (em L1), dessa maneira corroborando e expandindo os estudos de Schilperoord, que, além disso, se mostraram aplicáveis à produção de textos escritos. Todavia, ao comparar esses resultados com aqueles referentes a produção do texto traduzido (na L1), a autora encontrou duas diferenças interessantes. Primeiro, abaixo e no nível de oração, os intervalos entre as unidades eram mais longos nas traduções do que nas produções de textos monolíngues, apesar de a 
digitação ser na mesma língua (L1). Segundo, os intervalos eram progressivamente mais longos nas produções de textos traduzidos apenas até o nível da oração. Havia um nivelamento da diferença no caso dos intervalos entre as sentenças, e as durações das pausas eram mais curtas entre os parágrafos das traduções em comparação com aquelas encontradas no mesmo nível nas produções de textos monolíngues. Evidentemente, as desvantagens temporais envolvidas no trabalho em modo de tradução era mais que compensada pela vantagem de processamento envolvida em ser (geralmente) possível copiar a estrutura de uma sentença e não ter que planejar e estruturar o conteúdo no nível do parágrafo.

Tais achados fornecem fortes indícios ao pressuposto de que há uma correlação básica entre a ocorrência e a duração das latências na digitação de uma tradução e a quantidade de esforço de processamento despendido em dada localização dentro de uma unidade de processamento ou entre unidades. Os estudos da tradução precisam de muito mais experimentos desse tipo para descobrir em que medida tal padrão tão perfeitamente regular na distribuição de pausas se aplica, em termos gerais, aos pares de línguas e os diferentes níveis de expertise em digitação e transição entre telas.

\subsubsection{Alinhamento e triangulação dos dados de acionamentos de teclas e de dados do olhar}

Com a integração dos dados do olhar (gaze), a pesquisa do processo tradutório começou a procurar por um padrão similar. Carl $(2009 ; 2011)$ desenvolveu um método para visualizar os dados dos movimentos oculares e os de acionamentos de teclas e mouse e, além disso, alinhar esses dados com os itens do texto-fonte nos chamados gráficos de progressão. Em contraste com a triangulação dos dados qualitativos e quantitativos obtidos e gravados do mesmo evento de tradução, os gráficos de progressão dependem do alinhamento de duas fontes de dados quantitativos eletronicamente gravados, quais sejam, os conjuntos de dados de acionamentos de tecla e mouse e de dados do olhar, ambos alinhados (ainda manualmente) com itens dos texto-fonte. Tais gráficos fornecem uma visão geral do "perfil" do tradutor ou o comportamento tradutório no macronível e frequentemente ilustram (diferente/s) comportamento(s) nas três principais fases do processo tradutório: orientação inicial, redação e revisão final. Eles mostram imediatamente se um tradutor começou a ler alguma parte ou todo o texto-fonte antes de proceder à tradução propriamente dita. Mostram até que parte do texto um tradutor leu antes de digitar a tradução de um segmento. Mostram as regressões feitas pelo tradutor para retrabalhar no texto já traduzido na fase de redação, além de quando e como a revisão final foi feita (DRAGSTED; CARL, 2013). Desse modo, um gráfíco de 
progressão rapidamente identifica se um tradutor começa seu trabalho sem muita orientação inicial ou se apresenta uma orientação inicial mais cuidadosa; se é uma pessoa que usa mais ou menos contexto para se planejar na fase de redação; se revisa enquanto executa a tradução ou se deixa para o final; se recua demais etc.

O que se provou muito mais difícil (e, portanto, uma nova incógnita conhecida) é qual padrão pode ser identificado no micronível. Uma sugestão bastante preliminar, mas não amplamente informativa foi feita (por mim mesmo) em Alvstad et al. (2011). Nesse trabalhou, apontou-se uma sequência de seis passos, a qual se baseou na observação dos padrões de leitura/digitação em um desenho experimental com um texto-fonte na metade superior da tela e um espaço para inserção do texto-alvo na metade inferior da tela. Nessa sequência, foi introduzido o conceito de palavra(s) "âncora", tanto no texto-fonte quanto no texto-alvo já existente. No entanto, ainda são necessárias análises para se avaliar em que medida tal padrão teria suporte estatístico.

\subsection{Usos teóricos dos dados do processo tradutório}

Os gráficos de progressão são apenas uma forma de explorar os dados do processo tradutório. Os dados processuais de ambientes de tradução ou de pós-edição também podem ser utilizados para testar as hipóteses dos estudos da tradução a partir de uma nova perspectiva empírica (e.g., as atuais teorias sobre universais das traduções humanas, como explicitação, atração gravitacional e facilitação). A explicitação (ENGLUND DIMITROVA, 2007) descreve o fato de que, com bastante frequência e, quiçá, de forma universal, o significado que está apenas implícito no texto-fonte é expresso explicitamente no texto-alvo. Análises de gravações já existentes poderiam mostrar a prevalência (se não a universalidade) da explicitação nos nossos dados. A hipótese da atração gravitacional (HALVERSON, 2003) visa elucidar a ocorrência de uma super-representação, nas traduções, de certos fenômenos linguísticos "esquemáticos" salientes que não estão presentes na língua-fonte - uma hipótese que objetiva explicar observações familiares de normalização, simplificação, variação reduzida de formas/itens (types/tokens) etc. em textos traduzidos. A facilitação (ENGLUND DIMITROVA, 2007) refere-se à experiência de que a tradução de um texto longo se torna gradualmente mais fácil, em parte devido ao acúmulo de domínio do conhecimento específico e em parte devido à recorrência de expressões. Essa hipótese também poderia ser testada em

gravações existentes com base, por exemplo, na velocidade de produção textual e no comprimento dos segmentos. Se esses são de fato universais da tradução, podemos esperar 
manifestações de todas os três tanto nas atividades do tradutor/pós-editor como no seu produto final.

Os dados processuais também podem ser usados para testar a hipótese da tradução literal como procedimento padrão, formulada por Ivir (1981), uma hipótese intimamente relacionada com o modelo do mecanismo monitor formulado por Tirkkonen-Condit (2005), com a lei de interferência formulada por Toury (1995) e, possivelmente, com a hipótese da atração gravitacional (SCHAEFFER; CARL, 2014). Nesse caso particular, porém, parece que os estudos da tradução também podem se beneficiar de uma consulta ao que está sendo desenvolvido nas áreas vizinhas e talvez também possam ter algo a contribuir com elas. Uma hipótese básica nos estudos da tradução é a de que o primeiro impulso automático do tradutor é procurar por uma palavra na língua-alvo que seja formalmente similar ou idêntica àquela do texto-fonte. De acordo com o modelo do mecanismo monitor, é assim que a tradução ocorre, até que o mecanismo monitor entra em cena e interrompe esse processo padrão. Talvez uma consulta às áreas vizinhas possa nos ajudar a melhorar nosso entendimento dessa importante função ou "lei". Os neurolinguistas (DE BRUIN et al., 2014) observaram (a partir tanto de medições de eletrocardiogramas como a partir de imagens de ressonância magnética funcional) que nossos cérebros parecem distinguir nitidamente entre a inibição (que vem primeiro) e o monitoramento (que parece ser uma operação mais reflexiva) ${ }^{11}$. Será que as nossas hipóteses levam em conta essa distinção? Neurologistas e neurocientistas estão explorando os neurônios-espelho e a teoria da mente, enquanto psicólogos cognitivos vêm discutindo a teoria da "codificação comum", que relaciona percepção e ação. Em uma esteira similar, Pickering e Garrod (2013) lançaram a noção de um "emulador" em nosso cérebro, que está ativo tanto na compreensão quanto na produção da linguagem e espelha a produção durante a compreensão e vice-versa. A meu ver, ainda não foram exploradas as consequências dessa ideia para a maneira como o processamento da linguagem por um tradutor bilíngue pode vir a ser percebida. Embora nossa ideia geral sobre a interferência provavelmente não esteja errada, precisamos constantemente confrontar nossa teorias e hipóteses com o que está ocorrendo nas áreas de estudo vizinhas, se efetivamente quisermos aprimorar nossas hipóteses no âmbito dos estudos da tradução e se nossa ambição for efetivamente contribuir com áreas para além dos próprios estudos da tradução.

\footnotetext{
${ }^{11}$ Sou grato a Katharina Oster por essa informação.
} 


\section{Observações conclusivas: as incógnitas que permanecem}

Com as mudanças tecnológicas das últimas décadas, a concepção do que constitui a tradução passou por uma mudança considerável. A indústria cinematográfica, por exemplo, criou um novo e enorme mercado para habilidades de legendagem. A pós-edição de um texto traduzido automaticamente é outra esfera de atuação que requer um novo conjunto de habilidades, combinando as habilidades tradicionais de tradução do texto-fonte para o textoalvo, a habilidade de reformulação intralinguística e produção de textos originais, bem como noções de como funciona um sistema de tradução automática. Pela norma contemporânea, o tradutor não é mais um mediador neutro, um refletor passivo do significado. O tradutor agora é geralmente percebido como um agente responsável por garantir uma representação leal do significado do texto-fonte, é claro, mas também por garantir a legibilidade e compreensibilidade da comunicação, não só em termos de fazer sentido em outra língua, mas também em termos de ser facilmente acessível a leitores-alvo cujo conhecimento prévio talvez seja radicalmente distinto daquele dos leitores-alvo originais do texto. Sempre que a comunicação de experto para experto tem de ser passada a não expertos, há a necessidade de que o significado seja radicalmente reformulado, frequentemente tanto no aspecto interlinguístico quanto no aspecto intralinguístico. As transformações necessárias desde o estágio no qual o texto é circulado entre expertos até a sua chegada ao usuário final demandam habilidades linguísticas típicas do que se espera dos tradutores.

Talvez seja um tanto quanto surpreendente o fato de que Holmes mencionou a tradução automática e a tradução realizada com o apoio de ferramentas tecnológicas apenas em sua discussão sobre as teorias de tradução parcial (Seção 3.1221), desenvolvendo a ideia de distinções "restritas ao meio" entre tradução realizada por seres humanos (orais ou escritas), tradução realizada por máquinas e tradução realizada por um humano "em conjunto" com um computador. Esse último procedimento descreve a maneira como a maioria das traduções é produzida hoje em dia. A maioria das traduções agora é feita de forma "inteligente". O que isso significa é que as traduções não emergem da inteligência de um único tradutor humano, mas sim de um tradutor humano interagindo com um programa de tradução "inteligente" criado por uma equipe de especialistas em tradução e cientistas da computação, os quais são, de certo modo, coautores invisíveis, de forma que cada vez mais as traduções não têm um remetente pessoal e individual. Esse estado das coisas afetou nossa percepção da natureza da tradução, dos processos envolvidos, e gerou uma nova área não só para a teoria dos estudos da tradução, mas mais obviamente para os estudos descritivos da 
tradução.

Os estudos descritivos da tradução devem procurar descrever a natureza e a qualidade dessa nova interação entre o agente humano e a máquina (que, obviamente, foi programada para mediar o pensamento dos seres humanos, mas nem sempre tem sucesso em tal feito). Devem buscar descrever como esse novo estilo de produção afeta o(s) processo(s) e o produto. Para responder completamente às mudanças no modo como as traduções são produzidas atualmente, os estudos aplicados da tradução, conforme indicado por Holmes (1972), precisam incluir estudos de: como os programas de tradução automática, as memórias de tradução e as outras ferramentas de apoio à tradução são construídos; como as interfaces dos programas de tradução afetam os tradutores cognitivamente e talvez até ergonomicamente; e como as novas tecnologias afetam os locais de trabalho dos tradutores, social e economicamente. Também há considerações éticas distintas envolvidas quando não mais é possível identificar a responsabilidade autoral de um único indivíduo.

Para a maioria de tais linhas de investigação, os métodos empregados na pesquisa do processo tradutório são bastante adequados. As ferramentas de apoio à tradução são atualmente criadas de modo tal que, além de oferecerem sugestões de tradução baseadas no conhecimento que sistema tem do texto-fonte e na capacidade da sua tradução automática e da sua memória de tradução, no seu conhecimento de segmentos do TF atual que já foram traduzidos e no seu conhecimento de construções possíveis na língua-alvo e de continuações possíveis para uma oração emergente (i.e., além de tentarem adivinhar o texto do usuário mais rápido do que ele próprio), esses sistemas constantemente estudam e lembram as preferências do usuário e se adaptam para fornecerem um suporte otimizado à luz das necessidades e preferências do tradutor que os utiliza. O atual projeto CASMACAT (Cognitive Analysis and Statistical Methods for Advanced Computer-Aided Translation [Análise Cognitiva e Métodos Estatísticos para Tradução Avançada Auxiliada por Computador]) ${ }^{12}$, que conta com suporte financeiro da União Europeia, propõe a construção de uma próxima geração de ambiente de trabalho para o tradutor, a qual promete melhorar a produtividade, a qualidade e as práticas de trabalho na indústria da tradução. Um ponto interessante desse projeto é a sua tentativa de construir um ambiente de trabalho que integre o desenvolvimento do sistema com os resultados de estudos cognitivos do real comportamento do tradutor com base nos registros de acionamentos de teclas e no rastreamento ocular. Dados de comportamento dos usuários são examinados para melhor entender como as interfaces são utilizadas, para determinar os tipos e

${ }^{12}$ CASMACAT - Cognitive Analysis and Statistical Methods for Advanced Aided Translation. Disponível em: $<$ http://casmacat.eu>. Acesso em: 26 nov. 2017. 
estilos de tradutor, bem como para construir um modelo cognitivo do processo tradutório. Tudo isso significa que, quando da sua implementação na solução final do ambiente de trabalho eletrônico, o sistema, à medida que for usado por um tradutor, poderá estudá-lo e adaptar-se às suas necessidades e preferências específicas. O projeto estuda primariamente a pós-edição, considerando sugestões de tradução fornecidas por um sistema de tradução automática que opera interativamente com o usuário. Em outras palavras, qualquer insumo fornecido pelo tradutor imediatamente gera um novo conjunto de premissas para o sistema, com base nas quais serão feitas novas sugestões de tradução, inclusive previsões pontuais sobre como continuar ou completar uma sentença. Da parte do usuário, essa interatividade pode ser mediada não somente pela digitação em um teclado tradicional, mas também pode tomar lugar em outras modalidades, como por meio de uma caneta eletrônica ou por meio de informações referentes ao olhar que são atreladas a uma palavra em particular na tela. Em um projeto suplementar (SEECAT) ${ }^{13}$, estão sendo realizados experimentos com insumos falados em diferentes línguas e tratados por um sistema de reconhecimento de fala. Afinal, a interatividade e a multimodalidade na interação entre seres humanos e computadores estão atualmente definindo uma agenda importante no âmbito dos estudos da tradução.

Isso mostra como um novo ciclo recursivo de trabalho tem se desenvolvido em todas as principais ramificações dentro dos estudos da tradução. As contribuições das pesquisas descritivas de orientação tecnológica voltadas para os processos cognitivos e (micro)comportamentos dos tradutores são utilizadas no desenvolvimento de novas aplicações, que são projetadas não só para dar apoio ao usuário (o tradutor) por meio de vários tipos de sugestões, mas também para estudar o tradutor à medida que usa o sistema. Tudo isso leva a uma nova modelagem da tradução, uma nova teoria da tradução, em um processo interativo. Céticos podem indagar como os tradutores do futuro lidarão com o fato de se sentarem em uma galeria de espelhos. Todavia, o ciclo recursivo também pode ser visto como meio de integrar de forma muito mais robusta todos os elementos da utopia de Holmes para o campo disciplinar.

Os estudos da tradução também precisam se abrir ao que está sendo desenvolvido em áreas externas. É possível haver contínuos recuos à medida que tentamos nos aproximar de uma abertura da caixa preta e obter uma visão direta, ou ao menos uma espiadela, da atividade que ocorre na oficina mental do tradutor. Temos autoconhecimento e podemos falar sobre o

13 SEECAT Project: Speech \& Eye-Tracking Enabled CAT. Disponível em: $<$ https://www.cbs.dk/en/research/departments-and-centres/center-research-and-innovation-in-translation-andtranslation-technology/events/seecat-project-speech-eye-tracking-enabled-cat >. Acesso em: 26 nov. 2017. 
que pensamos que acontece no nosso cérebro, mas o que reportamos, por exemplo em um evento de tradução com verbalização concomitante do pensamento em voz alta, é apenas o que lembramos que estava na nossa mente. Como se gera o conteúdo dessa consciência do que pensamos que ocorre no nosso cérebro ainda é uma mera questão de especulação. O que vivenciamos na nossa mente ainda não está bem conectado com o que vemos e medimos do lado de fora ou até mesmo do lado de dentro do cérebro. Mesmo com o estudo neurolinguístico de potenciais relacionados a eventos, mesmo com as imagens fascinantes das áreas ativas do cérebro durante a realização de certas tarefas que obtemos em uma ressonância magnética funcional e mesmo com as promessas da neurociência, ainda estamos, do lado de fora, olhando para a caixa preta e para o que Holmes chamou de "ato de tradução propriamente dito". Podemos continuar especulando e teorizando, e nossa especulação e teorização explicarão tudo o que pensamos já se saber sobre o cérebro e a cognição, mas ainda estamos muito, muito longe de entender o "ato de tradução propriamente dito".

\section{Referências}

ALVES, F. Triangulating translation: perspectives in process oriented research. Amsterdã/Filadélfia: John Benjamins, 2003.

ALVSTAD, C.; HILD, A.; TISELIUS E. Methods and strategies of process research: integrative approaches in translation studies. Amsterdã/Filadélfia: John Benjamins, 2011.

BOWLES, M. The think-aloud controversy in second-language research. Nova York/Londres: Routledge, 2010.

BUTTERWORTH, B. Evidence from pauses in speech. In: speech and talk. Londres: Academic Press, 1980. p. 155-176. Language production:

CARL, M. Triangulating product and process data: quantifying alignment units with keystroke data. In: MEES, I. M.; ALVES, F.; GÖPFERICH, S. Methodology, technology and innovation in translation process research. Copenhagen: Samfundslitteratur, 2009. p. 225247.

CARL, M. Patterns of shallow text production in translation. In: SHARP, B.; ZOCK, M.; CARL, M.; JAKOBSEN, A. L. Human-machine interaction in translation: proceedings of the 8th International NLPCS Workshop. Frederiksberg: Samfundslitteratur, 2011. p. 143-151.

CARL, M.; DRAGSTED, B. Inside the monitor model: processes of default and challenged translation production. Translation: Corpora, Computation, Cognition, v. 2, n. 1, p. 127-145, 2012.

CHESTERMAN, A. Readings in translation theory. Helsinki: Finn Lectura, 1989. 
DANKS, J. S.; SHREVE, G. M.; FOUNTAIN, S. B.; MCBEATH, M. K. (Ed.). Cognitive processes in translation and interpreting. Londres: Sage Publications, 1997.

DE BRUIN, A.; ROELOFS, A.; DIJKSTRA, T.; FITZPATRICK, I. Domain-general inhibition areas of the brain are involved in language switching: fMRI evidence from trilingual speakers. NeuroImage, v. 90, p. 348-359, 2014.

DRAGSTED, B. Coordination of reading and writing processes in translation: an eye on uncharted territory. In: SHREVE, G. M.; ANGELONE, E. (Ed.). Translation and cognition. Amsterdã/Filadélfia: John Benjamins, 2010. p. 41-62

DRAGSTED, B.; CARL, M. Towards a classification of translation styles based on eyetracking and key-logging data. Journal of Writing Research, v. 5, n. 1, p. 133-158, 2013.

ERICSSON, K. A.; SIMON, H. A. Verbal reports as data. Psychological Review, v. 87, p. 215-251, 1980.

ERICSSON, K. A.; SIMON, H. A. Protocol analysis: verbal reports as data. Cambridge, MA: MIT Press, 1984 (ed. rev. 1993).

ERICSSON, K. A.; CHARNESS, N.; FELTOVICH, P. J. (Ed.). The Cambridge handbook of expertise and expert performance. Cambridge: Cambridge University Press, 2013.

FLOWER, L.; HAYES. J. R. A cognitive process theory of writing. College Composition and Communication, v. 32, n. 4: p. 365-387, 1981.

GERLO, P. Identifying the unit of analysis in translation: some uses of think-aloud protocol data. In: FÆRCH, C.; KASPER, G. (Ed.). Introspection in second language research. Filadélfia: Multilingual Matters, 1987. p. 135-158.

GOLDMAN-EISLER, F. Pauses, clauses, sentences. Language and Speech, v. 15, p. 103-113, 1972.

HOLMES, J. S. The name and nature of translation studies (1972). In: VENUTI, L. (Ed.). The translation studies reader. Londres/Nova York: Routledge, 2000. p. 172-185.

HÖNIG, H.; KUSSMAUL, P. Strategie der Übersetzung. Tübingen: Narr, 1982.

IMMONEN, S. Pauses in translation versus monolingual text production. Target, v. 18, n. 2, p. 313-336, 2006.

Inputlog. Disponível em: <http://www.inputlog.net/>. Acesso em: 29 maio 2014.

IVIR, V. Formal correspondence vs. translation equivalence revisited. Poetics Today, v. 2, n. 4, p. 51-59, 1981.

JAKOBSEN, A. L. Effects of think aloud on translation speed, revision, and segmentation. In: ALVES, F. (Ed.). Triangulating translation: perspectives in process oriented research. Amsterdã/Filadélfia: John Benjamins, 2003.

JAKOBSEN, A. L. Investigating translators' processing knowledge. In: DAM, H. V.; 
ENGBERG, J.; GERZYMISCH-ARBOGAST, H. (Ed.). Knowledge systems and translation. Berlim/Nova York: Mouton de Gruyter, 2005a. p. 69-95.

JAKOBSEN, A. L. Instances of peak performance in translation. Lebende Sprachen, v. 50, n. 3, p. 111-116, 2005b.

JAKOBSEN, A. L. Tracking translators' keystrokes and eye movements with Translog. In: ALVSTAD, C.; HILD, A.; TISELIUS, E. (Ed.). Methods and strategies of process research: integrative approaches in translation studies. Amsterdã/Filadélfia: John Benjamins, 2011.p. $37-55$.

JAKOBSEN, A. L.; JENSEN, K. T. H. Eye movement behaviour across four different types of reading task. In: GÖPFERICH, S.; MEES, I. M.; JAKOBSEN, A. L. Looking at eyes: eyetracking studies of reading and translation processing. Copenhagen: Samfundslitteratur, 2008. p. 103-124.

JUST, M. A. CARPENTER P. A. A theory of reading: from eye fixations to comprehension. Psychological Review, v. 87, p. 329-354, 1980.

JÄÄSKELÄINEN, R. Think-aloud protocol studies into translation: an annotated bibliography. Target, v. 14, n. 1, p. 107-136, 2002.

KRINGS, H. P. Was in den Köpfen von Übersetzern vorgeht. Narr: Tübingen, 1986.

KRINGS, H. P. Texte reparieren: empirische Untersuchungen zum Proze $\beta$ der Nachredaktion von Maschinenübersetzungen (Habilitationsschrift, 1995). Trad. para o inglês de Geoffrey S. Koby, Gregory M. Shreve, Katja Mischerikow e Sarah Litzer. Repairing texts: empirical investigations of machine translation post-editing processes. Kent/Ohio/Londres: Kent State University Press, 2001.

KUSSMAUL, P. Creativity in the translation process: empirical approaches. In: VAN LEUVEN-ZWART, K.; NAAIJKENS, T. (Ed.). Translation studies: The state of the art. Proceedings of the First James S Holmes Symposium on Translation Studies. Amsterdã: Rodopi, 1991. p. 91-101.

KUSSMAUL, P. Kreatives Übersetzen. Tübingen: Stauffenburg, 2000.

KUSSMAUL, P. Übersetzen - nicht leicht gemacht. Berlim: Saxa, 2009.

LEIJTEN, M.; VAN WAES, L. Inputlog: new perspectives on the logging of on-line writing. In: SULLIVAN, K. P.; LINDGREN, E. (Ed.). Computer key-stroke logging and writing: methods and applications. Oxford: Elsevier, 2006. p. 73-94.

LÖRSCHER, W. Translation performance, translation process, and translation strategies: a psycholinguistic investigation. Tübingen: Narr, 1991.

MESS, I. M.; ALVES, F.; GÖPFERICH, S. (Ed.). Methodology, technology and innovation in translation process research. Copenhagen: Samfundslitteratur, 2009.

NORD, C. Text analysis in translation: theory, methodology and didactic application of a model for translation-oriented text analysis. 2. ed. rev. Amsterdã/Nova York: Rodopi, 2005. 
PICKERING, M. J.; GARROD, S. An integrated theory of language production and comprehension. Behavioral and Brain Sciences, v. 36, n. 4, p. 329-347, 2013.

RADACH, R.; KENNEDY, A.; RAYNER, K. Eye movements and information processing during reading. Hove: Psychology Press, 2004.

RAYNER, K. Eye movements in reading and information processing: 20 years of research. Psychological Bulletin, v.124, n. 3, p. 372-422, 1998.

RAYNER, K.; POLLATSEK, A. The psychology of reading. Englewood Cliffs, N.J.: Prentice Hall, 1989.

REISS, K. Möglichkeiten und Grenzen der Übersetzungskritik. München: Hueber, 1971.

REISS, K. Texttyp und Übersetzungsmethode: der operative Text. Kronberg im Taunus: Scriptor, 1976.

REISS, K.; VERMEER, H. J. Grundlegung einer allgemeinen Translationstheorie. Tübingen: Niemeyer, 1984.

SCHILPEROORD, J. It's about time: temporal aspects of cognitive processes in text production. Amsterdã: Rodopi, 1996.

SCHAEFFER, M.; CARL, M. Measuring the cognitive effort of literal translation processes. In: GERMANN, U.; CARL, M.; KOEHN, P.; SANCHIS-TRILLES, G.; CASACUBERTA, F.; HILL, R.; O'BRIEN, S. (Ed.). Proceedings of the Workshop on Humans and Computerassisted Translation (HaCaT). Stroudsburg, PA: Association for Computational Linguistics, 2004. p. $29-37$

SÉGUINOT, C. The translation process: an experimental study. In: translation process. Nova York: H. G. Publications, 1989. p. 21-53. . (Ed.). The

SHARP, B.; ZOCK, M.; CARL, M.; JAKOBSEN, A. L. (Ed.). Human-machine interaction in translation: proceedings of the 8th International NLPCS Workshop. Frederiksberg:

Samfundslitteratur, 2011.

SHREVE, G.; ANGELONE E. (Ed.). Translation and cognition. Amsterdã/Filadélfia: John Benjamins, 2010.

STRÖMQVIST, S.; KARLSSON, H. ScriptLog for Windows. User's manual. Technical report. University of Lund: Department of Linguistics, and University College of Stavanger: Centre for Reading Research, 2002.

SULLIVAN, K. P. H.; LINDGREN, E. Computer key-stroke logging and writing: Methods and Applications. Oxford: Elsevier, 2006.

TIRKKONEN-CONDIT, S. The Monitor model revisited: evidence from process research. Meta, v. 50, n. 2, p. 405-414, 2005.

TOURY, G. Descriptive Translation Studies and beyond. Amsterdã/Filadélfia: John Benjamins, 1995. 
TOURY, G. Descriptive Translation Studies - and beyond. Revised edition. Amsterdã/Filadélfia: John Benjamins, 2012.

Translog. Disponível em: <http://translog.dk>. Acesso em: 29 maio 2014.

VENUTI, L. The translation studies reader. Londres/Nova York: Routledge, 2000. 